\title{
Hopo: The dread that clings
}

\section{Introduction}

Hopo is a term that has many definitions and explanations. This is complicated further by the fact that te reo Māori does not translate directly into English. There is very little literature concerning hopo. What does exist mainly explains hopo in spiritual terms. At the same time, hopo is mentioned very briefly in psychological terms. Supported by the extant literature, this paper will briefly explain hopo and recommend future research.

\section{Spiritual understandings of hopo}

A dear cousin had passed away tragically. Unfortunately, as the death had occurred overseas, there were significant delays concerning the tangihanga. When I saw my cousin in the coffin, I was overshadowed by a sense of dread and shock. As a result of this experience, I continued to see the image of my deceased cousin. The image seemed to be etched into my mind, and it was impossible to shake. In another incident, my cousins were digging 
a grave for a relative and mistakenly disturbed a much older grave nearby. The diggers were overcome with the intense smell of decomposition. The foul smell did not dissipate.

Both occurrences can be described as hopo. Hopo means to be fearful, apprehensive and overawed (Moorfield, 2011). My grandmother, Rēpora Marion Brown (1940-2017), described hopo as a sense, feeling, smell, an image in the mind, or a physical reaction in response to a dreadful experience. Concerning the first incident, I had told Nan that the image of my cousin 'haunted' me. Her response was, "you need to 'do yourself." What Nan meant was that only karakia would lift the image from my mind. In the second incident, karakia was performed by a tohunga of the Ringatū faith, and the dreadful smell disappeared.

As with other Māori emotions and concepts, hopo originates with Atua Māori, whakapapa, whānau, hapū, iwi, and te reo Māori (O’Toole \& Martin, 2019). Tom Roa described hopo as feelings of fear, apprehension, superstition, and being overawed due to a breach of tapu or tikanga (O'Toole \& Martin, 2019). Roa also explained that hopo may affect the transgressor or others and may result in illness (O’Toole \& Martin, 2019). Consistently, Paraone Gloyne maintained that "Hopo may be defined as a deep and intense psychological and spiritual fear resulting from a transgression of tikanga" (P. Gloyne, personal communication, June 26, 2021). 
Concerning matakite, Ronald Ngata's (2014) research defined hopo as an all-consuming fear. According to Hēmi-a participant in Ngata's (2014) work:

If you develop a hopo... the hopo becomes your enemy, because hopo is a fear which grows and grows and grows because you don't understand. When you can develop an understanding, you're okay. But when you cannot grow that understanding, it goes the other way and becomes a fear; and the more you fear, the worse it gets. It's all-consuming; it's all-consuming to the extent that you then have a problem with yourself. You can "lose it" in the sense that it consumes your whole life (pp. 189-190).

Interestingly, in 2000, Ngāti Wairere expressed concerns about the genetic modification of cattle (see Scott et al., 2000). For Ngāti Wairere, genetic modification was considered to interfere with whakapapa and mauri (Scott et al., 2000). As such, it was believed that potential risks and metaphysical consequences for them might include mate Māori, hopo, and death (Scott et al., 2000).

Consistent with Nan's solution-which, of course, is standard practice for Māori (Mead, 2016)-Roa expressed that hopo is remedied through karakia (O’Toole \& Martin, 2019). 


\section{Psychological understandings of hopo}

Hopo has been described as a "self-induced "depression" or deep grieving state" (Hirini, 2004, p. 39). A glossary published in the New Zealand Journal of Psychology defined hopo as a form of psychological withdrawal (Glossary of Maori words and phrases, 2005). Māori psychiatrist Hinemoa Elder (2020) defined hopo as fear, trepidation, and a feeling of dread. While hopo is a uniquely Māori cultural phenomenon, it may share some symptoms with Post Traumatic Stress Disorder (Hirini, 2004; Hirini et al., 2015). Indeed, how trauma and stress are expressed may be considerably divergent across cultures (Hirini, 2004; Hirini et al., 2015).

Intriguingly, Te Rita Papesch used the term hopo to refer to anxiety (Rātima \& Papesch, 2014). She described how she used waiata as a means of healing. According to Papesch: "he mea hei whakatau i te hopo, he mea whakatau ai i ngā raru/it reduces anxiety, it can quell the problems" (cited in Rātima \& Papesch, 2014, pp. 387-388).

\section{Conclusion}

This brief paper has pulled together what is published about the term hopo. There is a need for more work to be done around this complex and fascinating word. While the small literature was concerned with the spiritual and psychological aspects of hopo, in the future, the concept could be thoroughly examined in an in-depth study using 
inter-disciplinary research tools. Future research could also draw on other Indigenous experiences of hopo-like phenomena. 


\section{References}

Elder, H. (2020). Aroha: Māori wisdom for a contented life lived in harmony with our planet. Pengiun.

Glossary of Maori words and phrases. (2005). New Zealand Journal of Psychology, 34(1), 64. https://link.gale.com/apps/doc/A13267747 $1 /$ PPCJ?u=per_unit\&sid=bookmarkPPCJ\&xid=9d2c09ea

Hirini, P. (2004). A study of Mãori health care use: An evaluation of the Andersen Model [Unpublished doctoral thesis, Massey University]. Hirini, P., Flett, R., Long, N., \& Millar, M. (2005). Frequency of traumatic events, physical and psychological health among Māori. Criminal Justice, 34(1), 20-27.

Mead, H. M. (2016). Tikanga Mãori: Living by Mãori values. Huia.

Moorfield, J. C. (2011). Te Aka. Pearson.

Ngata, R. S. (2014). Understanding matakite: A Kaupapa Mãori study on the impact of matakite/intuitive experiences on wellbeing [Unpublished doctoral thesis, Massey University]. O'Toole V. and Martin R. (2019) The role of emotions in education in Aotearoa. In Kamp A (Ed.), Education studies in Aotearoa New Zealand: Key disciplines and emerging directions (pp. 179-200). NZCER Press. 
Ratima, M. T., \& Papesch, T. R. (2014). Te Rita Papesch: Case study of an exemplary learner of Māori as an additional language. International Journal of Bilingual Education and Bilingualism, 17(4), 379-393. https://doi.org/10.1080/13670050.2013.80643 $\underline{1}$

Scott, B., Huges, H., Falconer, B., Sutherland, O., Mantell, C., \& Welsh, L. (2000). An application by AgResearch to the Environmental Risk Management Authority concerning genetically modified cattle. Māori Law Review. http://maorilawreview.co.nz/2000/08/august2000-contents/ 